\title{
EFFICIENCY OF LOW COST ADSORBENTS FOR THE REMOVAL OF ARSENIC FROM WATER
}

\author{
Megh Raj Pokhrel* \\ Raghu Nath Dhital
}

\begin{abstract}
Adsorption is one of the primary processes for removing arsenic from drinking water. This study focuses on developing inexpensive and effective adsorbents to remove arsenic from ground water. Eight different types of adsorbents were prepared. Some of these materials were chemically modified. The efficiency of percentage adsorption of arsenite, As(+III) on different materials were investigated at different $p H$, contact time and initial concentrations. Out of eight different types of adsorbents, the iron-loaded xanthated orange waste (Fe-XOW) showed high efficiency for the removal of arsenic. It was found that approximately $83 \%$ of arsenite, As $(+I I I)$ and $87 \%$ of arsenate, $A s(+V)$ removal could be achieved at optimum $p H$ of 10 and 4 respectively. The significant effect of $\mathrm{pH}$ was in the range of 9 to 12 for As (+III) and 3 to 5 for As $(+V)$. Time dependency experiments for the arsenite uptake showed that the adsorption rate on $\mathrm{Fe}-\mathrm{XOW}$ was fast initially for 1 hour, followed by slow attainment of equilibrium at 2.15 hour. Adsorption isotherm test showed that equilibrium adsorption data were better represented by Langmuir model than the Freundlich model and the maximum adsorption $\left(q_{\max }\right)$ for As $(+I I I)$ onto $\mathrm{Fe}-\mathrm{XOW}$ was found to be $53.47 \mathrm{mg} / \mathrm{gm}$. The concentration of arsenic in water sample was determined by standard silver diethyldithiocarbamate spectrophotometric method (SDDC method).
\end{abstract}

Key words: arsenate, arsenite, xanthated orange waste, adsorption.

\section{INTRODUCTION}

Arsenic occurs widely in nature and is best known for its toxic properties. Arsenic occurs in four different oxidation states (-III, 0, +III and +V) but in natural water it is mostly found in inorganic form as oxyanions of trivalent arsenite, $\left(\mathrm{As}^{3+}\right)$ or pentavalent arsenate, $\left(\mathrm{As}^{5+}\right)$. Arsenite is more toxic, mobile and more stable than arsenate in aqueous solution especially at $\mathrm{pH}$ greater than 7 . Hence it is difficult to remove arsenite as compared to arsenate due to higher stability in natural water by simple adsorption and precipitation processes (Nagarnaik, 2002). Although there is no widely accepted mechanism of the release of arsenic in ground water but it has been accepted that most of all including in Nepal is of natural geological origin (Panthi, et al., 2006).

Drinking arsenic rich water over a long period can result in various adverse health effects including skin problems, skin cancer, cancers of bladder, kidneys and lungs, disease of the blood vessels of the legs and feet, and possibly also diabetes, high blood pressure and reproductive disorders. Arsenic

Mr. Pokhrel is a Professor at Central Department of Chemistry, T.U., Kirtipur, Kathmandu, Nepal. 
contamination of drinking water resources is a global crisis. However, this problem is more acute in countries like Bangladesh, India, Taiwan, China and Terai belt of Nepal (Pokhrel et al. 2009, Bissen et al., 2000). Therefore, processes to remove arsenic from drinking water are urgently required.

Numerous arsenic removal technologies such as co-precipitation, liquidliquid extraction, ion exchange, ultrafiltration, adsorption etc. have been so far used for arsenic removal. Among them, adsorption methods are considered to be most promising technologies because of simplicity to operate and cost effective. Many attempts have been made regarding the removal of arsenite and arsenate by using iron(III) loaded chelating ion exchange resins having their acidic or basic moiety as functional group. But treatments with the resins are expensive and not affordable to the people of developing countries (Biwas et al., 2008, Ghimire et al. 2003). In this regard, efficiency of some low cost adsorbents prepared from some cheap biomasses and other materials for the removal of arsenite and arsenate from aqueous solution have been investigated in this work.

\section{METHODOLOGY}

All chemicals, $\mathrm{As}_{2} \mathrm{O}_{3},\left[\mathrm{~Pb}\left(\mathrm{CH}_{3} \mathrm{COO}\right)_{2}\right], \mathrm{SnCl}_{2} .2 \mathrm{H}_{2} \mathrm{O}, \mathrm{Na}_{2} \mathrm{HAsO}_{4} \cdot 7 \mathrm{H}_{2} \mathrm{O}$, $\mathrm{C}_{4} \mathrm{H}_{9} \mathrm{NO}, \mathrm{FeCl}_{3}$ used were of reagent grade. Silver diethyldithiocarbamate was of A.R. grade which was used without any further purification.

\section{PREPARATION OF ADSORBENTS}

\section{Unmodified adsorbents}

About $1 \mathrm{~g}$ of hematite was taken and it was converted into fine powder form and dried in hot air oven at about $80^{\circ} \mathrm{C}$ for an hour. The fine powdered form of brick red (BR) and red mud (RM) was prepared as hematite.

\section{Modified adsorbents}

\section{Iron (III)-loaded rice husk (Fe-RH)}

Fresh rice husk was collected from a local rice mill and was passed through different sieve size. The fraction of particle between 425 and $600 \mu \mathrm{m}$ (geometric mean size: $505 \mu \mathrm{m}$ ) was selected. Rice husk was washed thoroughly with distilled water and was dried at $60^{\circ} \mathrm{C}$. The material thus obtained was designated as raw rice husk. For modification, the dried and sieved rice husk was treated with $\mathrm{HNO}_{3}$ in 1:2 ratios, and $3 \mathrm{gm}$ of acid treated rice husk was mixed with $500 \mathrm{~mL}$ of $1.5 \times 10^{-2} \mathrm{M} \mathrm{Fe}$ (III) solution having $\mathrm{pH} 3$ and stirred in rotary shaker at room temperature for 24 hours. The product (designated as Fe-RH) was washed with water until neutral and dried for 24 hour at $40^{\circ} \mathrm{C}$ (Ong et al., 2007).

\section{Iron (III)-loaded sugarcane bagasse (Fe-SCB)}

Raw sugarcane bagasse was collected from the juice center. It was cut into small pieces, washed several times with distilled water and dried in an oven at $100^{\circ} \mathrm{C}$ for 24 hours. The adsorbent was then grinded and sieved to get the desired particle size of 300 to $425 \mu \mathrm{m}$ and subjected to acid modification with $\mathrm{H}_{2} \mathrm{SO}_{4}$ in 1:2 ratios. The iron (III) was loaded using the same procedure as in the case of rice husk.

\section{Iron Coated Sand (Fe-CS)}

$200 \mathrm{gm}$ of sand was immersed in an acid $(20 \% \mathrm{HCl})$ solution for 24 hour and was dried. Acid treated sand was mixed with $2 \mathrm{M}$ ferric chloride $(80 \mathrm{~mL})$ and 
$10 \mathrm{M}$ sodium hydroxide $(4 \mathrm{~mL})$. The product (designated as Fe-S) was heated in an oven at $110^{\circ} \mathrm{C}$ for 14 hour and washed with distilled water until neutral and then dried for 24 hours at $40^{\circ} \mathrm{C}$ (Vithanage et al., 2007).

\section{Fe (III)-loaded xanthated orange waste (Fe-XOW)}

Orange waste after juicing were collected from juice centre and crushed into small size. The crushed orange wastes were dried in an oven for 48 hours at $70^{\circ} \mathrm{C}$. The dried wastes were further grounded into small sizes.

For the modification, the dried raw orange waste $(20 \mathrm{gm})$ was treated with $50 \mathrm{~mL}$ of $18 \% \mathrm{NaOH}$ and stirred for 1 hour then $10 \mathrm{~mL}$ of $\mathrm{CS}_{2}$ was added and the mixture was stirred in rotary shaker at room temperature for $24 \mathrm{~h}$. Thus obtained product was washed with water until neutral and dried for 24 hour at $40^{\circ} \mathrm{C}$ and sieved to obtain uniform particle size. The adsorbent now hereafter called as XOW-gel. Then iron (III) was loaded on XOW-gel (Fe-XOW) following the same procedure as in the case of rice husk (Ghimire et al., 2002).

\section{Fe (III)-loaded xanthated apple waste (Fe-XAW)}

Apple waste after juicing were collected and crushed into small size. The crushed apple wastes were dried in an oven for 48 hours at $70^{\circ} \mathrm{C}$. The dried wastes were further grounded into small sizes. It was then chemically modified and iron (III) was loaded as in the case of orange waste adsorbent. The adsorbent now hereafter called as Fe-XAW.

\section{Adsorption studies}

\section{Effect of pH on arsenic removal}

Adsorption of arsenic as a function of $\mathrm{pH}$ was examined in a series of experiments where the initial concentration was maintained constant $(2 \mathrm{mg} / \mathrm{L})$ at varying $\mathrm{pH}$ from 2-12. $\mathrm{pH}$ of the solution was adjusted by adding small amount of $\mathrm{NaOH}(1 \mathrm{M})$ or $\mathrm{HCl}(1 \mathrm{M})$. From such experiments, the optimum $\mathrm{pH}$ value for arsenic (III and V) adsorption onto the adsorbents was obtained. All batch adsorption experiments were carried out in $125 \mathrm{~mL}$ stoppered bottles with $25 \mathrm{mg}$ of the adsorbents with $25 \mathrm{~mL}$ of initial working solution of arsenic. The bottles were then agitated on a rotary shaker at room temperature for 24 hours. After $24 \mathrm{~h}$, the suspensions were filtered immediately and the filtrate was analyzed for arsenic concentration. The concentrations of arsenic before and after adsorption were determined by Silver Diethyldithiocarbamate Spectrophotometric Method (SDDC method). Absorbance was recorded by using WPA S-104 spectrophotometer (UK) using $1 \mathrm{~cm}$ glass cuvette. From arsenic concentrations measured before and after the adsorption $\left(\mathrm{C}_{\mathrm{o}}\right.$ and $\mathrm{C}_{\mathrm{e}}$, respectively) and dry weight of adsorbent (W), as well as volume of aqueous solution (V), the amount of arsenic adsorbed (q) was calculated according to the equation

$$
\mathrm{q}=\frac{\mathrm{C}_{\mathrm{o}}-\mathrm{C}_{\mathrm{e}}}{\mathrm{W}} \times \mathrm{V}(\mathrm{mg} / \mathrm{g})
$$

The removal percentage ( $\mathrm{R} \%$ ) was calculated according to the equation

$$
\mathrm{R}(\%)=\frac{\mathrm{C}_{\mathrm{o}}-\mathrm{C}_{\mathrm{e}}}{\mathrm{C}_{\mathrm{o}}} \times 100
$$


The $\mathrm{pH}$ of the solution before and after the adsorption was adjusted and monitored using Digital $\mathrm{pH}$ meter (WPA CD 300).

\section{Effect of contact time on arsenic removal}

After determining the optimum $\mathrm{pH}$, equilibrium time for adsorption of arsenite onto Fe- $\mathrm{XOW}$ was studied at optimum $\mathrm{pH}$ and room temperature. For this $25 \mathrm{~mL}$ of $2 \mathrm{mg} / \mathrm{L}$ of arsenite solution was taken in a $125 \mathrm{~mL}$ stoppered bottle with $25 \mathrm{mg}$ of adsorbent. The suspension was equilibrated in a mechanical shaker for different time intervals from 15 to 150 minutes. The suspensions were then filtered immediately and analyzed by SDDC method.

\section{Isotherm Studies}

The isotherm studies were conducted at room temperature by varying the initial concentration of arsenic solutions ranging from $5 \mathrm{mg} / \mathrm{L}$ to $250 \mathrm{mg} / \mathrm{L}$. The adsorptions were carried out by shaking $25 \mathrm{~mL}$ of arsenite solution with $25 \mathrm{mg}$ of Fe-XOW for $24 \mathrm{~h}$ in a mechanical shaker. The arsenic concentrations after adsorption were analyzed by SDDC method. This study helps in evaluating the maximum adsorption capacity of arsenic onto different low cost adsorbents.

\section{RESULTS AND DISCUSSIONS}

Effect of pH on adsorption of arsenite onto various chemically modified and unmodified adsorbents

It is well known that the $\mathrm{pH}$ of the medium affects the solubility of metal ions and the concentration of the counter ions on the functional groups of the adsorbent, so $\mathrm{pH}$ is an important parameter affecting the adsorption of metal ions from aqueous solution. Figure 1 shows the relationship between removal percentage and equilibrium $\mathrm{pH}$ on the adsorption of arsenite onto chemically modified and unmodified adsorbents at an initial concentration of $2 \mathrm{mg} / \mathrm{L}$. The arsenite uptake by different types of chemically modified and unmodified adsorbents was found to be very sensitive to $\mathrm{pH}$ variation at the examined range of $\mathrm{pH}$ from 6-13. The removal of arsenite by adsorption onto different types of adsorbents was found to increase up to $83 \%$ in the highly alkaline medium. 
Figure 1: Effect of $\mathrm{pH}$ on adsorption of arsenite onto various low cost adsorbents

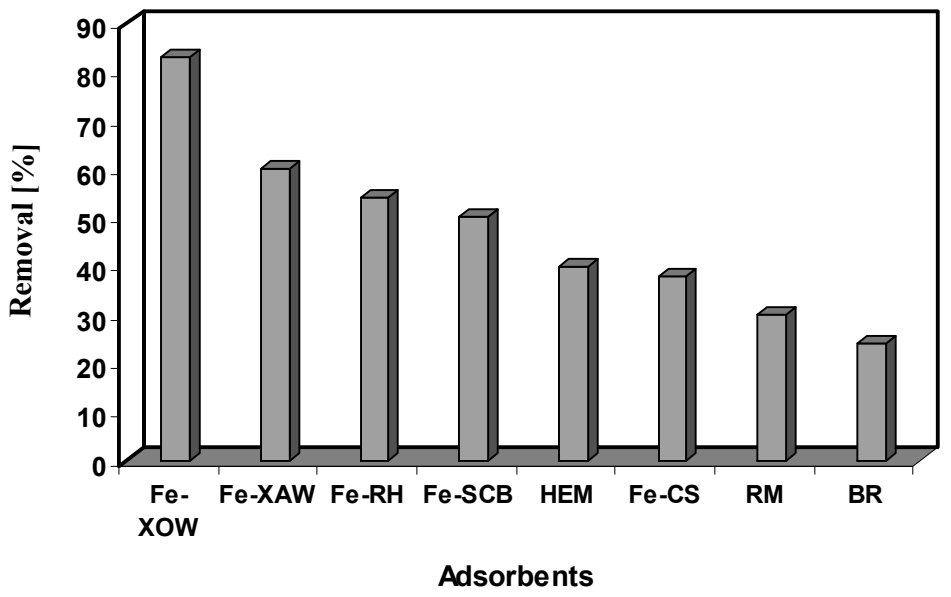

From Figure 1 it is clear that out of eight different types of adsorbents $\mathrm{Fe}$ XOW has high efficiency for the removal of arsenic. About $83 \%$ of arsenite was adsorbed on the Fe-XOW at optimum $\mathrm{pH}$ of 10 . While only $60,54,50,40,38,30$ and $24 \%$ of arsenite adsorption was found onto the Fe (III)-loaded xanthated apple waste (Fe-XAW), Fe (III)-loaded rice husk (Fe-RH), Fe (III)-loaded sugarcane bagasse (Fe$\mathrm{SCB}$ ), hematite (HEM), Fe-coated sand (Fe-CS), red mud (RM) and brick red (BR) at optimum $\mathrm{pH}$ of $10,12,12,12,12,12$ and 10 respectively.

Figure 2: Comparison of adsorption of arsenite onto various adsorbents at optimum $\mathrm{pH}$

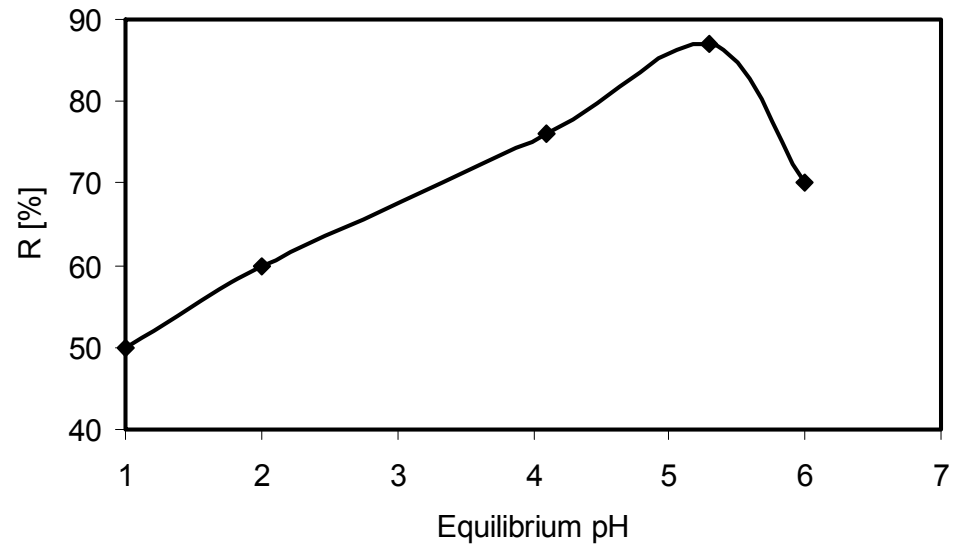

Figure 2 shows the results of comparative studies of removal [\%] of arsenite by various modified and unmodified adsorbents. The adsorption 
increases rapidly near the optimum $\mathrm{pH}$ range hence $\mathrm{pH}$ of solution has significant effect on the adsorption of arsenite.

Effect of $\mathrm{pH}$ on adsorption of arsenate onto Fe-loaded xanthated orange waste (Fe-XOW)

Figure 3 shows the adsorption of arsenate onto Fe-XOW at an initial concentration of $2 \mathrm{mg} / \mathrm{L}$. The $\mathrm{pH}$ of solution plays an important role for adsorption. It is considered that Fe (III) is adsorbed by releasing protons from the phosphorylated unit of cellulose according to cation exchange mechanism. The adsorbed iron will co-ordinate ocatahedrally with hydroxyl ions and neutral water molecules that are available in aqueous medium.

Figure 3: Effect of $\mathrm{pH}$ for adsorption of arsenate onto Fe(III)-loaded XOW

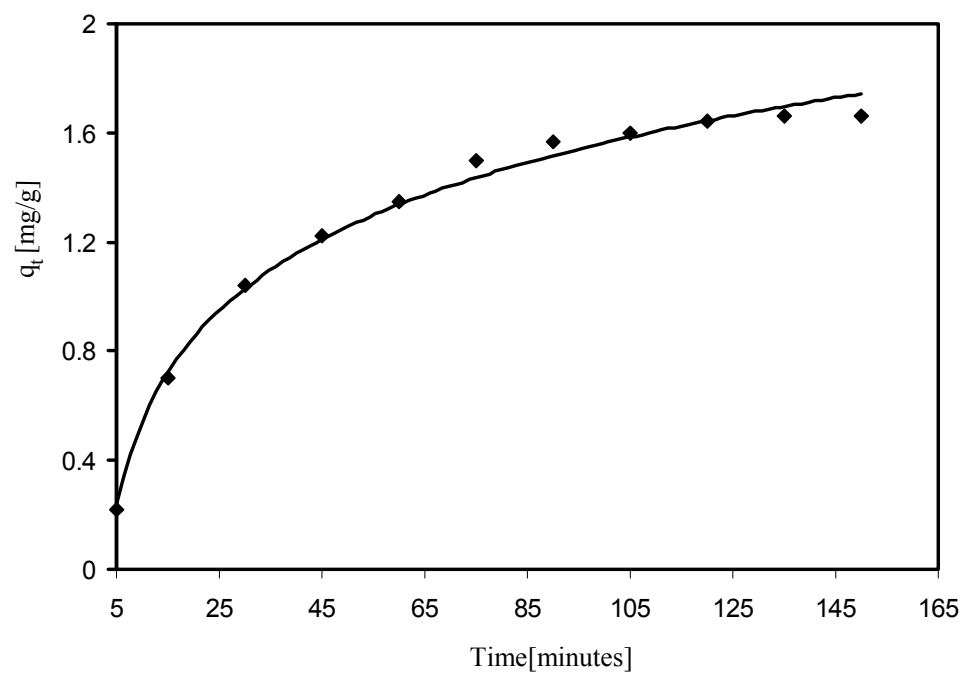

The adsorption of arsenic will take place by releasing hydroxyl anion from the above mentioned co-ordination sphere. For this reason, the adsorption of arsenic species onto Fe-XOW is termed as ligand exchange adsorption. But the fate is decided only in the presence of Fe (III). This is the reason why Fe (III)loaded materials are being used for arsenic removal (Ghimire et al., 2000 ). It is clear from the Figure 3 that approximately $87 \%$ of arsenate was adsorbed onto the $\mathrm{Fe}-\mathrm{XOW}$ at an initial concentration of $2 \mathrm{mg} / \mathrm{L}$ at optimum $\mathrm{pH}$ of 4 . Optimum adsorption of arsenate was observed in acidic medium, whereas arsenite adsorption was found in weakly alkaline medium.

\section{Equilibrium time studies}

Figure 4 shows the adsorption of arsenite onto Fe-XOW from 15 to 150 minutes $(2.5 \mathrm{~h})$. The adsorption of arsenite was found to be constant after $2.15 \mathrm{~h}$. Thus the required equilibrium time for the adsorption of arsenite onto Fe-XOW was $2.15 \mathrm{~h}$. Time dependency experiments for the arsenite uptake showed that the adsorption rate on Fe- XOW was fast initially for 1 hour, followed by slow attainment of equilibrium at 2.15 hours. 
Figure 4: Effect of contact time on adsorption of arsenite onto Fe-XOW

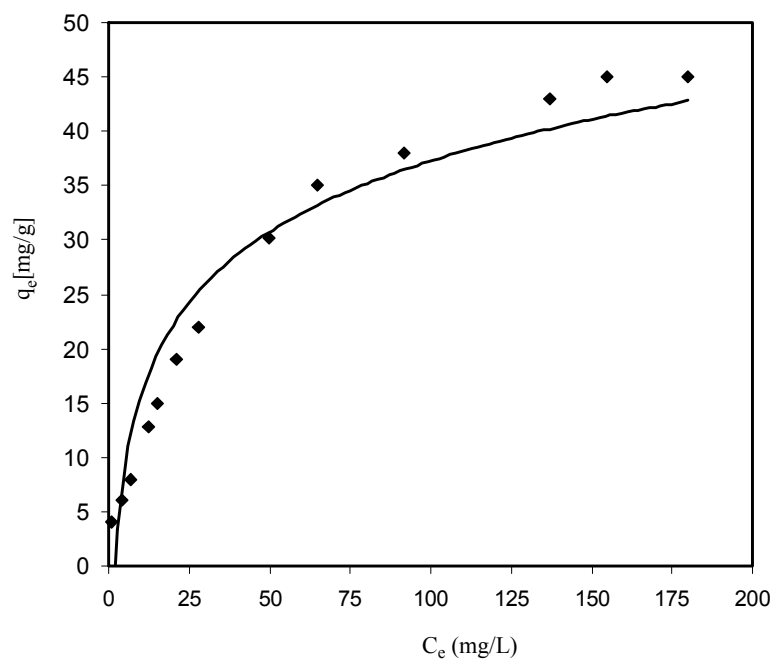

The arsenic adsorption capacity is rapid initially because of the presence of large number of anion exchange sites. When all the active sites are occupied by arsenite then adsorption remains constant.

\section{Isotherm studies}

The main objective of isotherm study is to evaluate the capacity of the modified adsorbents to sequester As(III) from an aqueous solution. It was done by characterizing the equilibrium state of the Fe-XOW adsorbent that has been allowed to react with aqueous solution of As(III).

Figure 5 shows the adsorption isotherm for As(III) onto the Fe-XOW. It is seen that the adsorption of As (III) increases with the increase in equilibrium arsenite concentration.

Figure 5: Adsorption isotherm of arsenite by Fe-XOW

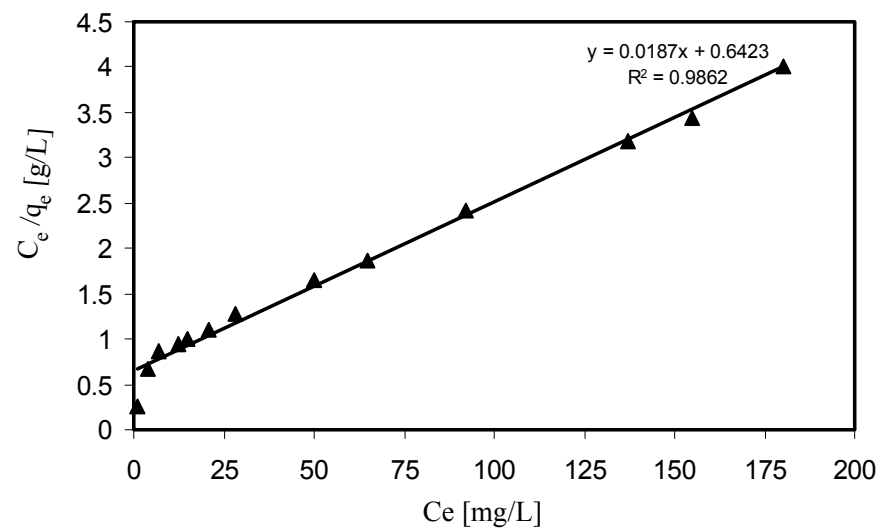


Uptake of arsenite is eventually limited by the constant number of active sites and resulting plateau of isotherm. This is because, at lower arsenite concentration, the ratio of the initial moles of arsenite to the available surface functional group is low, but at higher concentration, the available functional sites of the adsorbent become fewer compared to the moles of arsenite present and hence the uptake of metal ion becomes independent upon the initial metal ion concentration.

\section{Adsorption isotherm model}

Adsorption of As(III) onto Fe-XOW gives the linear relationship with Langmuir and Freundlich isotherms which are shown in Figure 6 and 7 . Langmuir and Freundlich parameters are determined from the slope and intercept of the plots of $c_{e} / q_{e}$ versus $c_{e}$ and $\log q_{e}$ versus $\log c_{e}$ respectively.

Figure: 6 Langmuir isotherm plot for adsorption of arsenite onto Fe- XOW

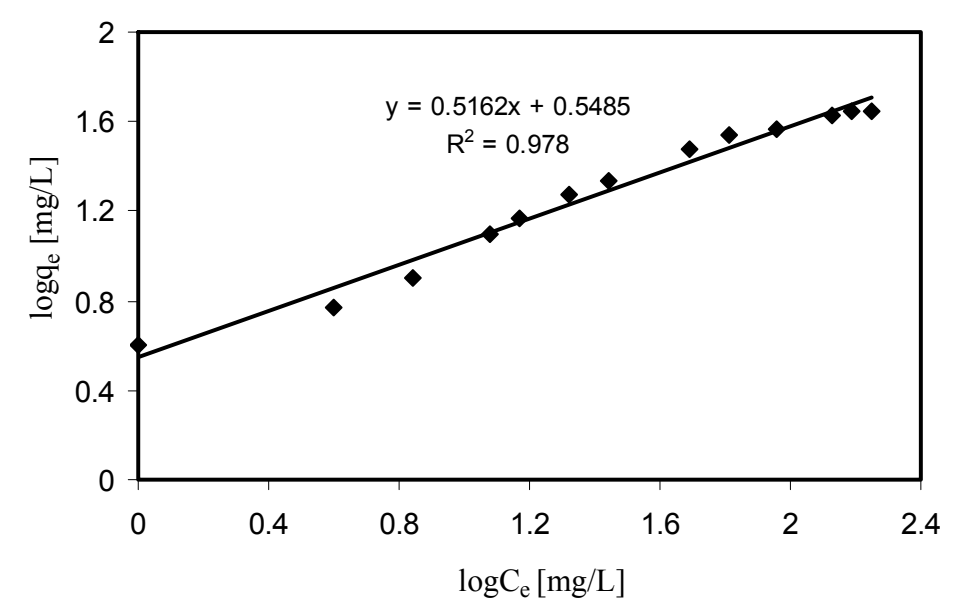

Figure 7: Freundlich isotherm plot for adsorption of arsenite onto Fe-XOW

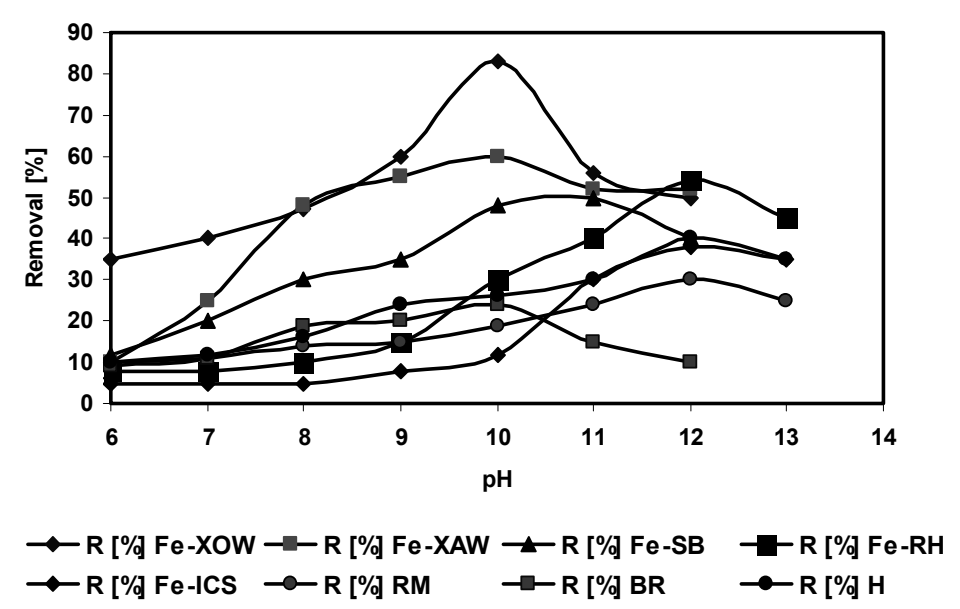


The results obtained are presented in the Table 1 . A comparatively high value of correlation coefficient for Langmuir adsorption as compared to Freundlich adsorption isotherm indicates that the adsorption process more closely fits to the Langmuir isotherm model.

Table 1: Langmuir and Freundlich adsorption isotherm parameters and correlation coefficient with experimental $\mathrm{q}_{\max }$

\begin{tabular}{|c|c|c|c|c|c|c|}
\hline \multicolumn{3}{|c|}{ Langmuir isotherm } & \multirow{2}{*}{$\begin{array}{c}\text { Experimenta } \\
\mathbf{l}\end{array}$} & \multicolumn{3}{|c|}{ Freundlich isotherm } \\
\cline { 1 - 1 } $\mathbf{q}_{\mathbf{m a x}}(\mathbf{m g} / \mathbf{g})$ & $\mathbf{b}(\mathbf{L} / \mathbf{m g})$ & $\mathbf{R}^{2}$ & $\begin{array}{c}\mathbf{K}(\mathbf{m g} / \mathbf{g}) \\
\mathbf{q}_{\mathbf{m a x}}(\mathbf{m g} / \mathbf{g})\end{array}$ & $\mathbf{1} / \mathbf{n}$ & $\mathbf{R}^{\mathbf{2}}$ \\
\hline 53.47 & 0.642 & 0.986 & 48.00 & 3.535 & 0.516 & 0.978 \\
\hline
\end{tabular}

The more favorable adsorbent is indicated by the higher value of slope of an isotherm. From the slope, the maximum adsorption capacity of $\mathrm{Fe}-\mathrm{XOW}$ was found to be $53.47 \mathrm{mg} / \mathrm{g}$ for As(III).

\section{Analysis of Sample Water of Nawalparasi and Rupandehi Districts}

The natural water samples collected from different tube wells of Devdaha VDC of Rupandehi District and Jahada and Manahari VDC of Nawalparasi district were analysed for arsenic content by silver diethyldithiocarbamate spectrophotometric method (SDDC). Then samples were subjected to adsorbent treatment with $\mathrm{Fe}-\mathrm{XOW}$. The results of the analysis were presented in the Table 2 .

Table 2: Arsenic concentration in water samples determined by silver diethyldithiocarbamate spectrophotometric (SDDC) method

\begin{tabular}{|c|l|l|c|c|c|}
\hline $\begin{array}{c}\text { Sample } \\
\text { No. }\end{array}$ & Districts & VDC & $\begin{array}{c}\text { Initial } \\
\text { concentration } \\
\text { (ppb) }\end{array}$ & $\begin{array}{c}\text { Equilibrium } \\
\text { concentration } \\
\text { (ppb) }\end{array}$ & $\begin{array}{c}\text { \% } \\
\text { Adsorption } \\
\text { of arsenic }\end{array}$ \\
\hline A & Nawalparasi & Manahari & 360 & 180 & 50 \\
\hline B & Nawalparasi & Jahada & 250 & 120 & 52 \\
\hline C & Nawalparasi & Jahada & 300 & 135 & 55 \\
\hline D & Rupandehi & Devdaha & 400 & 200 & 50 \\
\hline E & Rupandehi & Devdaha & 230 & 92 & 60 \\
\hline F & Rupandehi & Devdaha & 350 & 161 & 54 \\
\hline
\end{tabular}

The results show that only $50-60 \%$ of arsenic removal was achieved from the collected water samples which is less than arsenic removal from the synthetic solution. This low arsenic removal from the water sample may be due to the competitive adsorption of arsenic, phosphate, silicate and other ions present in the water samples.

\section{CONCLUSION}

In this study different types of chemically modified and unmodified adsorbents were prepared and their efficiency for the removal of arsenic [III and $\mathrm{V}]$ from water was analyzed. The effect of $\mathrm{pH}$ in the adsorption of arsenite onto chemically modified and unmodified adsorbents at an initial concentration of 2 $\mathrm{mg} / \mathrm{L}$ was investigated. The adsorption of arsenic was dependent on $\mathrm{pH}$ of solution, initial concentration of adsorbate and contact time. The $\mathrm{pH}$ of the 
solution has shown to be one of the key variables for arsenic removal. It was found that out of eight different types of adsorbents Fe-XOW has high efficiency for the removal of arsenic from water. It adsorbed approximately $83 \%$ of total arsenite and $87 \%$ of arsenate present in the water at optimum $\mathrm{pH}$ of 10 and 4 respectively. The equilibration time and maximum adsorption $\left(\mathrm{q}_{\max }\right)$ for the adsorption of arsenite onto the Fe-XOW was found to be 2.15 hour and 53.47 $\mathrm{mg} / \mathrm{gm}$ respectively.

Arsenic content of water samples of Nawalparasi and Rupandehi district was analyzed by standard silver diethyldithiocarbamate spectrophotometric method (SDDC). The samples were subjected to adsorbent treatment with Fe-XOW for the removal of arsenic. Only $50-60 \%$ of arsenic removal was achieved from the water sample which is less than arsenic removal from the synthetic solution. This low arsenic removal from the water samples may be due to the competitive adsorption of arsenic, phosphate, silicate and other ions present in the water samples.

\section{ACKNOWLEDGEMENT}

The authors are very thankful to the Head of Central Department of Chemistry, Tribhuvan University, Kirtipur, Kathmandu, Nepal for providing the available research facilities to conduct this work.

\section{WORKS CITED}

Bissen, M.; Frimmel, F.H. (2000). Speciation of As(III), As(V), MMA and DMA in contaminated soil extracts by HPLC-ICP/MS. Fresenius J. Anal. Chem. 367, 51-55.

Biwas, B.K.; Inoue, K.; Ghimire, K.N.; Harada, H.; Ohto, K.; Kawakita, H. (2008). Removal and recovery of phosphorus from water by means of adsorption onto orange waste gel loaded with zirconium. Bioresource Tech. 99, 8685-8690.

Ghimire, K.N., Inoue, K., Yamaguchi, H., Makino, K., Miyajima T. (2002). Adsorptive Removal of Arsenic Using Orange Juice Residue, Sep. Sci. and Tech., 37(12), 2785-2799.

Ghimire, K.N.; Inoue, K.; Makino, K.; Dhakal, R.P. (2003). Adsorptive removal of arsenic and fluoride by using orange juice residue. Hydrometallurgy. 2, 1937-1950.

Nagarnaik, P. B., Bhole, A.G., Natarajan, G.S. (2002). “Arsenic Removal of Ground Water - a State of Art”. Water Resources Journal. December 51-66.

Ong, Soon-An, Seng, Chye-Eng, Lim, Poh-Eng (2007). Kinetics of Adsorption of $\mathrm{Cu}(\mathrm{II})$ and $\mathrm{Cd}(\mathrm{II})$ from Aqueous Solution on Rice Husk and Modified Rice Husk. EJEAF Che.. B(2), 1764-1774.

Pokhrel, D.; Bhandari, B.S.; Viraraghavan, T. (2009). Arsenic contamination of ground water in the Terai region of Nepal. An overview of health concerns and treatment options. Environment International. 35, 157-161.

Vithanage, M., Chandrajith, R., Bandara, A., Weerasooriya, R. (2006). Mechanistic Modelling of Arsenic Retention on Natural Red Earth in Simulated Environmental Systems. J. Colloid Interf. Sci. 294 (2), 265- 272. 